\title{
Path of Constructing Ecological Innovation and Entrepreneurship College in Universities
}

\author{
${ }^{1}$ Guangdong Ocean University, Zhanjiang, Guangdong, China \\ ${ }^{2}$ Guangdong Ocean University, Zhanjiang, Guangdong, China \\ ${ }^{3}$ Guangdong Ocean University, Zhanjiang, Guangdong, China \\ ${ }^{4}$ Guangdong Ocean University, Zhanjiang, Guangdong, China \\ a254821302@qq.com \\ bsungaoang@126.com \\ c369145450@qq.com \\ dsociology_rongshan@163.com
}

Zuo Lihua ${ }^{1, a}$, Sun Gaoang ${ }^{2, b}$, Yan Lan ${ }^{3, c}$, Liu Rongshan ${ }^{4, d}$

\begin{abstract}
The construction of ecological innovation and entrepreneurship education system is an important measure in response to the national "encourage youth growth, support youth entrepreneurship". At present, the construction of innovation and entrepreneurship colleges in China is in full swing. But there are still much problems, such as the insufficient construction of teaching staff, the serious disconnection between theory and practice, and the imperfect support mechanism. In order to promote the development of innovation and entrepreneurship education in universities, we should strengthen the top-level design, build an ecological innovation and entrepreneurship college, and attach importance to practical education, collaborative education and all-people's education. By building a "pyramid" type four-level classroom education system. Taking education guidance, competition service, practice service and fund management as the four "centers". The leadership mechanism and working mechanism of multi department, internal and external cooperation are established. And the ecological innovation and entrepreneurship college with industry characteristics, school characteristics and professional characteristics is built.
\end{abstract}

Key words: Ecological, Innovation and Entrepreneurship College, Path of Constructing, Practice Platform

\section{高校建设生态型创新创业学院路径探析}

\author{
左利华 $1, \mathrm{a}$ ，孙高昂 $2, \mathrm{~b}^{*}$ ，严岗 $3, \mathrm{c}^{* *}$ ，刘荣山 ${ }^{4, \mathrm{~d}^{* * *}}$
}

'广东海洋大学学业和发展中心, 湛江, 广东, 中国

2 广东海洋大学管理学院, 湛江, 广东, 中国

3 广东海洋大学管理学院, 湛江, 广东, 中国

${ }^{4}$ 广东海洋大学法政学院, 湛江, 广东, 中国

a254821302@qq.com

$b^{*}$ sungaoang@126.com

c**369145450@qq.com

$d^{* * *}$ sociology_rongshan@163.com

\section{摘要}

建设生态型创新创业教育体系是响应国家 “鼓励青年成长, 支持青年创业” 的重要举措。为促进高校创新创业 教育发展，应强化顶层设计建设生态型创新创业学院，重视实践教育、协同育人、全民教育。通过打造 “金字 塔” 式的四级课堂教育体系, 以教育指导、竞赛服务、实践服务、基金管理为四个 “中心” 抓手, 建立多部门、 校内外协同配合的领导机制和工作机制, 建设具有行业特征、学校特色、专业特点的生态型创新创业学院。 
关键词: 生态型, 创新创业学院, 建设路径, 实践平台

\section{1.前言}

十九大报告中提出: 坚持“鼓励创业带动就业, 促 进高校毕业生等青年群体多渠道就业创业”为导向, 并指出要“鼓励青年成长, 支持青年创业”。[1]近年来, 为了满足基于知识的经济和社会发展的迫切需要, 全 国高校纷纷成立创新创业学院, 将创新创业工作从就 业服务工作中分离出来。在大力推进高校创新创业教 育的基础上，如何更好的完善创新创业教育体系、明 确发展定位和发展目标、适合新时代发展要求的创新 创业人才培养要求。基于此, 建设一个生态型创新创 业学院是新时代高校发展创新创业教育的重要选择。

\section{2.生态型创新创业学院的建设意义}

\section{1. 建设创新型国家的重要手段}

创新型国家的核心要求是大幅度提高科技创新 能力, 而高校历来是科技创新的主阵地。我国正处在 建设创新型国家和世界科技强国的伟大进程中, 需要 一批高水平创新型大学作支撑。高校只有通过深化高 等教育体制改革, 构建以市场为导向、产学研深度融 合的技术创新体系, 积极倡导创新文化、创业精神, 强化知识产权创造、保护、运用, 才能培养造就一大 批具有国际水平的战略科技人才、科技领军人才、青 年科技人才和高水平创新团队。生态型创新创业学院 建设是创新人才培养的支持点, 通过增加对教师、学 生、创客等创新创业活动的投入, 以高校特有人才高 地、科技进步和技术创新优势引领创新型国家的建设。

\section{2. 培养创新创业实践型人才的重要抓手}

新时代社会的发展迫切需要新知识、新技术、新 业务、新理念和新的生产方式产生的综合人才。学生 只有具备了创新的思维和创业实践的能力才能跟上 社会发展的需要。为此, 高校必须审时度势的建设生 态型创新创业学院, 将创新创业教育融入人才培养体 系, 贯穿人才培养全过程, 优化创业教育师资结构, 吸纳有实践经验的创业者、职业经理人和其他专业人 员加入师资队伍, 积极搭建创新创业实践平台, 为学 生未来创新创业活动开展提供无限的知识技能支撑。

\section{3. 建设创新型大学的必然要求}

现代大学在服务国家发展、引领社会文明、增进 人类福祉等方面承担起重要使命, 而创新则不断推动 着现代大学走向经济社会大舞台。衡量一所高校的办
学水平高低不仅仅要看这所高校的办学历史、办学规 模、校园面积、经费投入等指标, 更为重要的是要看 能否培养出与社会经济、产业发展、企业需求相匹配 的人才, 看能否培养出适应新时代社会发展需求的创 新创业人才。只有以创新立校、人才强校, 做好创新 创业人才的培养, 着力建设创新创业教育体系, 满足 社会需求, 将专业教育融入创新创业教育, 不断提升 学生的创新创业素质, 才能建设好高质量创新型大学。

\section{3.创新创业学院建设存在的问题}

尽管创新创业学院已经成为各高校的基本标配, 全国创新创业教育也如火如茶的展开达数年之久, 然 而学生的创业热情并没有因此而得到显著的提高。[2] 很多高校的创新创业学院教育体系不够完善, 教育形 式单一, 教育内容缺乏活力, “闭门造车”, 创新创业 教育脱离社会、缺乏实践有关。[3]

\section{1.师资队伍建设不足}

校内创新创业教师素质不高。教育部早在 2016年 就要求所有高校必须开设创新创业教育类课程, 并纳 入学分管理, 要求配置优质师资力量, 保证创新创业 课程质量。然而汇总相关师资信息发现，部分地方高 校的创新创业教育师资严重不足, 大多数均为校内其 他学科教师兼职, 多为辅导员及各学科的专业负责人 兼任，几乎没有专职教师。师资结构不合理、创业师 资队伍资源的调配单一、校内外教师比例不协调、创 业师资队伍的多样性不足。

校外创业导师的聘用不足。创新创业教育依然停 留在校内不同部门的配合, 闭门造车, 缺少与企业、 政府等校外资源的互动, 聘请实战经验丰富的校外导 师有限, 校外导师也未能真正参与创新创业的培养过 程。创业导师最主要来源于校内专家学者, 缺乏实战 经验, 往往只能教出来“赵括”式的创业者。

\section{2. 理论与实践严重脱节}

以大班集中上课的形式开设创新创业通识课程, 缺乏课堂互动、缺少实践锻炼、缺乏实训操作, 使学 生对所学知识只停留在理论层面, 无法有效指导学生 的创业实践活动。理论与实践严重脱节主要体现在以 下两个方面: 一是高校在推动创新创业教育课程建设 时存在各部门单打独斗、各自为政的状态; 二是高校 的创新创业教学活动与外部社会和企业相对独立, 缺 乏与社区、企业及整个社会的衔接。[4] 


\section{3. 创新创业教育支持机制不健全}

创新创业的实践性决定了高校的支持机制要向 实践方向倾斜, 注重实践投入, 重视实践教学。[5]为 此, 高校创新创业实践基地的配套建设程度也直接关 乎着创新创业人才的培养水平。现今国内许多高校的 创新创业实践基地的建设明显存在着配套不到位、场 地不足等问题, 一定程度上阻碍了部分学生创新创业 实践活动的展开。同时, 实践教育弱化、项目扶植不 到位、创业基金不足等支持机制不健全都是制约创新 创业教育发展的重要因素。

\section{4.生态型创新创业学院的建设路径}

\section{1.生态型办学定位}

\subsection{1. 明确学校人才培养目标}

创新创业学院的建设要与高校的人才培养目标 相一致, 重视创新实践型人才培养。针对创新型人才 的培养发展战略的要求, 制定创新创业教育大纲。创 新创业学院的人才培养方案也要结合本校的办学层 次、专业实际、发展特色, 提出支持学生开展科学研 究、技术开发和创新创业实践的可行性教育方案。

\subsection{2. 明确创新创业教育的定位}

大学生创新创业教育有四个方面的定位: 第一是 立足于应用型人才培养; 第二是服务于地方经济发展; 第三是注重构建应用型学科体系; 第四是贴近创业实 际。[6]要结合自身的办学条件和专业基础, 从专业的 角度、应用的角度、市场的角度培养创新创业能力, 重视学生的动手能力, 着重培养专业应用型、创业实 践型人才。

\subsection{3. 明确创新创业教育的目标}

创新创业教育的目标不是简单的看有多少学生 毕业前后自主创业, 而应该是综合评价学生的创业素 质、创业能力、创新能力。[7]要处理好专业教育与创 业教育、就业教育的关系。先就业, 在企业、行业进 一步锻炼, 待条件成熟再自主创业也是创业教育的目 标。应该将创新创业教育融入人才培养全过程, 既要 保证专业教育的完整性, 又要培养学生的创业知识、 创业意识、创业素质、创业能力。[8]

\section{2.生态型办学方向}

\subsection{1.重视创业实践教育}

着重建设创业实训中心、创业孵化基地、大学生 科技园等创新创业实践基地。以实践教育促进理论教 育的学习, 改变传统教育重理论、轻实践的弊端。充 分利用碎片化、高参与等成人学习的优势, 使用成人
教学法开展丰富多彩的教学活动, 充分调动学生的兴 趣, 提高学习效果。以项目选拨、交流和实训为手段, 让学生在实践中掌握创业知识。重点做好实践指导、 创业竞赛、企业调研、商事服务、项目对接等实践活 动。

\subsection{2. 强调协同育人}

校内协同：协同专业教育、科技创新、创业孵化 基地、思想政治教育、就业指导、竞赛指导、创新创 业训练平台, 以创新创业学院牵头整合校内资源, 成 立创业教育领导机构, 统筹全校的创新创业教育, 千 头万绪一条线、齐心协力一根绳, 构建多元化的创新 创业教育育人机制。

高校协同：立足本校，利用本区域、本专业领域 的兄弟院校相关资源，结合专业特色和区域特色，建 立创新创业教育联盟，分享创新创业教育资源、交流 教育经验, 协作创新、扬长补短, 提升教育质量。

社会协同: 协同政府机关、社会类创业孵化机构、 投资机构、校友会、创客组织等社会资源。整合相关 “引进来”的社会资源，为学生提供最大限度的支持服 务, 支持创业项目“走出去”, 引导和鼓励优质的创业 项目走向社会，提高创新创业项目活力。

\subsection{3. 强调全民教育}

创新创业教育不仅要面向全校学生, 也要面向已 毕业的校友、有创业意愿的社会人士和企业管理人员。 在校大学生与社会人员共同参与学习, 充分利用双方 在理论和实践方面的优势, 扬长补短, 让理论碰撞实 践产生创新的火花, 更好的点燃创业激情。

\section{3. “金字塔”式的创新创业教育课堂建设}

\subsection{1.第一课堂 (通识平台)}

设置创业教育通识课程模块。把创新创业教育融 入专业教育全过程中, 在人才培养方案中设置创新创 业教育通识模块，传授专业前景知识、管理发展知识 和综合素质知识等, 培养学生的创新创业素质。

$\mathrm{SYB} / \mathrm{KAB}$ 创业培训规模化。充分利用较为成熟 的 SYB/KAB 创业培训, 利用头脑风暴法、创业游戏 等高参与性教学方法, 使用视觉教具、项目答辩等教 学形式, 让学生构思合理的创业项目、掌握登记注册 税收的流程、了解市场营销的方法, 了解如何创办企 业, 让学生具备创业的基本能力。

开设创新创业类辅修专业。注重辅修专业实践教 育, 对考察合格的学生授予辅修专业证书。将创业实 践、创新创业竞赛活动与创新创业教育对接, 实施理 论学分与实践学分互认, 鼓励学生以理论联系实践的 形式完成教育教学活动, 引导学生参与创新创业实践 活动。 


\subsection{2.第二课堂（拓展平台）}

开展创业讲座、论坛、沙龙等创业教育活动。组 成以校内专家、政府工作人员、企业家、投资人等为 主体的师资队伍，通过沙龙、考察、论坛等课外拓展 活动, 系统的开展创业素质、创业项目选择、创业指 导、风险控制和创业励志等方面的教育。

实施“企业家进校园”工程。结合各专业实践的要 求, 邀请成功创业的校友、知名企业家等进校园, 以 自身经验指导在校学生的创业活动。实行创业导师制, 引导学生做好专业实践应用研究, 一对一指导有创业 项目的学生, 打磨具有特色的创新创业项目, 促进创 业项目落地。

打造二级学院创新创业教育“品牌”工程。结合专 业特点, 引导各二级学院围绕创新型人才培养目标开 展创业教育“品牌”工程, 以校内竞赛、创业实践指导、 项目孵化为抓手, 形成学院特色、专业特点的创业品 牌项目。

\subsection{3. 第三课堂 (拔高平台)}

开展创新创业竞赛活动。以“挑战杯”“互联网+” 等创新创业大赛和各级各类学科创新技能大赛为抓 手, 面向全校学生开展学科创新大赛、创新创业大赛、 创业技能大赛等竞赛活动, 以赛促学、以赛促创, 并 将创业大赛成绩与理论教学考核学分互认, 强化赛事 育人功能。

实施创新创业训练项目。充分发动学生参与大学 生创新创业训练项目, 鼓励和支持学生结合所学专业 开展科学研究、创新研究、创业训练, 鼓励学生勤思 考、多动手, 从实践的角度理解专业问题, 激发创新 创业潜能, 提供研究试错机会, 提升学生对创新创业 的认识水平。

培育创业社团。支持并培育学生创新创业类社团, 充分发挥朋辈效应, 指导学生社团开展形式多样的活 动, 广泛吸收凝聚有意愿创业的大学生, 营造浓厚的 创业氛围, 树立创新创业实践典型, 提供创新创业交 流的机会, 提升大学生创新创业活力。

搭建创业交流平台。加强创业教育的信息化建设, 设立专门的网站, 建立交流平台, 搭建起企业家、政 府机关、投资人、创客和大学生之间的网络交流平台。 充分利用网络空间, 为创业大学生学习政策和行业信 息、学习行业经验、寻找合作伙伴和投资人等知识创 造条件。

\subsection{4.第四课堂（培优平台）}

校内创新创业实践平台建设。充分利用国家、省 市相关政策, 全力打造与学校发展相适应的大学生创 新创业实践平台。建设睬化基地、科技园等实践平台, 结合专业特色和营销创新, 选拔较为成熟的创业项目 进行孵化, 通过基地系统的实践训练, 指导创业项目
落地。

校外创新创业实践平台建设。与校外各类创新创 业实践平台对接，充分利用校外资源，定期组织创业 项目到成熟企业进行交流，让创业项目走出“象牙塔”。 对接一批专业涵盖面广、实践性强的校外创新创业实 践平台, 为创业初期学生提供充分认识社会的机会, 改变大学生创业项目“见光死”的怪象, 提高初创企业 的存活率。

\section{4 建设四个“中心”抓手}

\subsection{1.创业教育指导中心}

以创新创业教学教研室的师资力量为基础, 搭建 起校内专家、校外导师的交流平台, 负责创新创业教 学活动开展。规范管理全校创业通识课程、创业培训 和辅修专业教育教学活动, 做好辅修专业、课外培训、 实践学分认定等教学活动。针对学生需求, 制定系统 的实践教学计划, 举办多种形式的教育教学活动。

\subsection{2. 创业竞赛服务中心}

对接省市和国家的各类创业大赛, 组织开展专业 技能、学科知识、创新创业等竞赛活动。深挖优质项 目, 对参赛项目进行赛前培训、赛中管理、赛后交流, 促进优质创业项目落地, 鼓励专业教师参与创新创业 竞赛活动, 营造浓厚的创新创业氛围。

\subsection{3. 创业实践基地服务中心}

维持创新创业实践基地的正常秩序, 深挖校内产 学研创新创业项目, 选拔优质项目进行瞬化。负责对 创新创业团队进行思想先进性教育, 利用一切社会资 源为进驻团队提供技术支持与咨询服务。加强对外交 流, 联系对接校外创新创业实践平台, 为创新创业捊 化项目提供进一步发展的机会。

\subsection{4. 创业基金管理中心}

做好创业基金的管理和评审工作，对接引入天使 投资、政府扶植基金等资金资源，为优质创业项目争 取资金支持。完善基金评审制度，以“成熟一个、扶植 一个”的原则，旨在选拔并扶植市场前景良好的创业 项目, 适当降低创新创业活动的试错成本, 提升学生 的创新创业信心。 


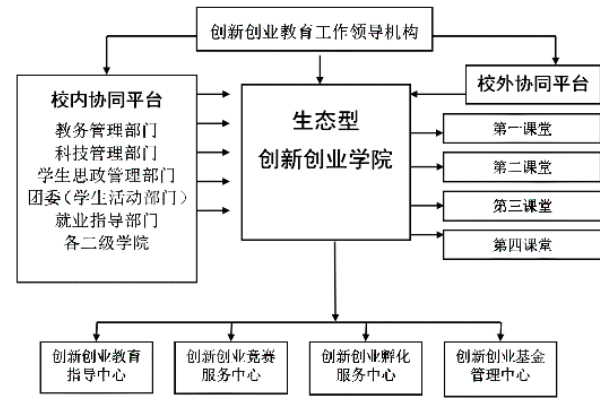

图 1 生态型创新创业学院建设框架图

总之, 生态型创新创业学院的建立, 需要从高校 领导层面成立创业教育领导机构; 充分整合校内外资 源, 充分发挥大学生创新创业的能动性; 以四个“中心” 抓手, 细化创新创业教育模块, 进一步强化实践实训 功能; 重点关注“四个课堂”的建设，构建“金字塔”式 的立体创新创业教育体系，促进创新创业项目的流动 和发展。学校要建立多部门协同配合的领导机制和工 作机制，建立完善的促进大学生创新创业教育的工作 制度，提出具有行业特征、学校特色、专业特点的实 施办法。争取各类社会力量, 建设内外兼修、专兼共 舞的师资队伍, 加强创新创业教育实践平台建设, 为 学生提供“走出去”的创新创业发展机制。

\section{5.结论}

本文基于各高校大学生创新创业情况, 提出建设 生态型创新创业教育体系。现阶段各高校建设创新创 业学院有师资队伍建设不足、理论与实践严重脱节、 创新创业教育支持机制不健全等问题, 根据存在的问 题从生态型办学定位、生态型办学方向、“金字塔”式 的创新创业教育课堂建设等方面提出合理的生态型 创新创业学院的建设路径。

\section{项目资金}

本研究受广东省高等教育教学研究和改革项目 (GD2018301) 资助, 项目名称: 大学生创新创业实 践教育的机制建设研究。

\section{REFERENCES}

[1] Jinping, X. Decisive victory in building a moderately prosperous society in all respects and winning the great victory of socialism with Chinese characteristics in the new era -- report at the nineteenth National Congress of the Communist Party of China [N] People's daily, October 28, 2017 (1).

[2] Mycos Research Institute. Employment report of Chinese college students in 2018 (Blue Book of employment) [R]. Address: Beijing, June 11, 2018.

[3] Wang Meixia.Investigation on the current situation of College Students' innovation and entrepreneurship education and countermeasures [J] Employment of college students in China. 2018 (3): 34-39.

[4] Zhuo Zelin, Zhao Zhongjian. Construction and Enlightenment of innovation and entrepreneurship education ecosystem in high level universities $[\mathrm{J}]$ Research on education development. 2016 (3): 64-71.

[5] Li Jiahua, Lu Xudong. Integrating innovation and entrepreneurship education into university talent training system $[\mathrm{J}]$. China higher education, 2010 (12): 9-11.

[6] Li Changping et al. Orientation and development path of entrepreneurship education [J]. Educational theory and practice. 2016 (8): 28-31.

[7] Tan lizhang, Qian Jinjin.Research on improving the effectiveness of entrepreneurship education based on entrepreneurship practice. Research on higher engineering education. 2015 (1): 140-143.

[8] Chen Xi. Innovation and entrepreneurship education throughout the whole process of talent training in Colleges and universities [J]. China higher education, 2010 (12): 4-6. 